\title{
硫酸鉛結晶薄膜の作製と感湿特性
}

\author{
菅＼cjkstart禎彦・平松友康 ·金子文隆* ·難波典之 \\ 関東学院大学，236-8501 神奈川県横浜市金沢区東六浦 1-50-1 \\ *湘南工科大学，251-8511 神奈川県藤沢市辻堂西海岸 1-1-25
}

\section{Crystalline Lead Sulfate Films Grown by Electron Beam Epitaxy and its Humidity-Sensitive Characteristics}

\author{
Yoshihiko SUGA, Tomoyasu HIRAMATSU, Fumitaka KANEKO* and Noriyuki NANBA \\ Kanto Gakuin University, 1-50-1, Higashi Mutsuura, Kanazawa-ku, Yokohama-shi 236-8501 \\ *Shonan Institute of Technology, 1-1-25, Tsuiidou Nishi Kaigan, Fuiisawa-shi 251-8511
}

\begin{abstract}
Crystalline thin films of lead sulfate, $\mathrm{Pb}_{1+y} \mathrm{SO}_{4+z}(y=0$ or $1,0 \leqq z \leqq 1)$ could be prepared by an electron beam method with using a source of $\mathrm{PbSO}_{4}+x \mathrm{PbO}(0 \leqq x \leqq 1)$, under the following conditions: substrate temperature; $300^{\circ} \mathrm{C}$, acceleration voltage; $20 \mathrm{kV}$ and emission current; $58 \mathrm{~mA}$. The sulfate films formed were composed of $\mathrm{PbSO}_{4}$ or $\mathrm{Pb}_{2} \mathrm{SO}_{5}$, and their compositions of the films changed with changing source composition. Either single phase of $\mathrm{PbSO}_{4}(y=0, z=0)$, or $\mathrm{Pb}_{2} \mathrm{SO}_{5},(y=1, z=1)$, or a mixture of these phases was formed with the source composition of $x=0, x=1$, or approximately $x=0.5$, respectively. Evaluation of the humidity sensitivity for these films revealed that crystalline thin films of $\mathrm{PbSO}_{4}$ and $\mathrm{Pb}_{2} \mathrm{SO}_{5}$ had the hydrophobic and hydrophilic properties, respectively, being one of the most promising humidity sensors because of quick response.

[Received March 5, 2002; Accepted December 19, 2002]
\end{abstract}

Key-words : Lead sulfate, Thin film, As-grown, Humidity sensor, Humidity response, Compositional control

\section{1. 緒 言}

近年，センサーを用いたマイコン制御が応用される中，湿度 センサーはエアコン, 加湿器, 除湿機等の空調機器, またオー ブン, 電子レンジ等の調理機器の湿度検知に実用化されてき た。中でも焼結体の多孔質を利用したセラミック湿度センサー は細孔円に水分が凝集する毛細管凝縮を利用して抢り，この構 造上の特徵が湿度センサー材料に生かされ1)，広く使用されて きた。しかし，凝集した水分子は容易に脱離しないため，間欠 的に加熱リフレッシュを必要とするものが多い2．

これに対し，水分子を吸着しやすい親水性と吸着しにくい疎 水性が材料組成により決定される母体制御型3),4) の感湿材料て は水分子の粒界 ·気孔による毛細管凝縮ではなく，材料固有の 親水性, 疎水性によって水分子の吸着 - 脱着性が決まるため, 湿度変化による水分子の吸着と脱着が容易に進行する。した がって，母体制御型の感湿材料は良好な湿度応答性を有し，リ フレッシュを必要としないという利点がある。このような特徵 を利用する湿度センサ一材料として，厚膜焼結体の湿度特性は 詳細に検討されているが ${ }^{5)}$, 焼結体には粒界が数多く存在する ため，母体制御型の感湿機構に粒界·気孔による感湿機構が重 畳している可能性がある。これらの粒界や気孔の影響を低減す るためには薄膜化が望ましい．また素子の小型化，IC 化の観 点からも薄膜化は重要であり, 成膜, 露光, エッチング, ドー ピング等の技術からなるプレーナプロセス6)を考えると，ポス トアニールの工程を必要としない, as-grown での結晶化が求 められる。

本論文では母体制御型の材料である硫酸鉛7)に注目し，電子 ビーム蒸着法により as-grown で硫酸鉛の結晶薄膜化を行っ た．更に，これらの素子の感湿性，湿度応答を測定して，硫酸 鉛の感湿機構の解明をし，湿度センサーへの応用を考える.

\section{2. 実 験}

薄膜作製には電子ビーム蒸着装置（日本真空技術製，EBV-
6DA）を用いた.ソースには $\mathrm{PbSO}_{4}+x \mathrm{PbO}(0 \leqq x \leqq 1)$ 粉末を 混合, 焼成し，バルクとして使用した．基板には石英を用い, 薄膜作製条件は基板温度 : $150 \sim 350^{\circ} \mathrm{C}$, 電子ビームの Emission 電流 : $58 \mathrm{~mA}$, 蒸着時真空度 : $5 \times 10^{-4} \mathrm{~Pa}$ 以下とし, 蒸 着時間を $1 \mathrm{~h}$ とした。こうして得られた蒸着速度は約 $8 \mathrm{~nm} / \mathrm{s}$ であった。生成相の同定にはX線回折装置（理学製，No. 2037, $\mathrm{Fe} \mathrm{K} \alpha, 35 \mathrm{kv}, 10 \mathrm{~mA}$ ) を用いた.

作製した薄膜の感湿性は, 周囲温度を $30^{\circ} \mathrm{C} に$ 保った恒温恒 湿槽内（いすず製， $\mu-251 \mathrm{~F})$ に薄膜を設置し，相対湿度を変 えて薄膜のインピーダンスを測定した。なお，測定には LCZ メータ（エスエフ回路設計ブロック製, 2430 LCZ METER) を用い， $\mathrm{AC} 1 \mathrm{~V} ，$ 周波数 $1 \mathrm{kHz}$ を印加して測定した.

\section{3. 結果及び考察}

\subsection{X 線回折による結晶性の評価}

硫酸鉛の結晶薄膜化温度を知るために，基板温度を $150^{\circ} \mathrm{C}$ $350^{\circ} \mathrm{C}$ とて作製した薄膜の $\mathrm{X}$ 線回折パターンを図 1 に示す. 参照のために一番下に硫酸鉛バルク $\left(\mathrm{PbSO}_{4}, \mathrm{~Pb}_{2} \mathrm{SO}_{5}\right)$ の $\mathrm{X}$ 線回折パターンを加えた。ソースの組成比が $\mathrm{PbSO}_{4}+x \mathrm{PbO}, x$ $=0.0$ (a)の場合には, 特定の面方位に配向しているためか, 強度は一致していないものの, 基板温度の变化によらず $\mathrm{PbSO}_{4}$ のピークが観測でき， $300^{\circ} \mathrm{C}$ を゙基板温度の上昇とと

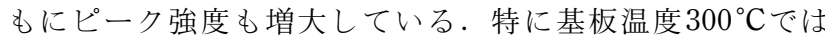
$\mathrm{PbSO}_{4}(021)$ ピークの急激な増大が見られる. 一方，ソースの 組成比が $\mathrm{PbSO}_{4}+x \mathrm{PbO}, x=1.0$ (b)の場合も配向性が見られる が，基板温度の上昇とともにピーク強度が増加しており，300 ${ }^{\circ} \mathrm{C}$ で最も強い $\mathrm{Pb}_{2} \mathrm{SO}_{5}(310)$ ピークが観測できる。 また，どち らの場合も基板温度が $300^{\circ} \mathrm{C}$ 超えるとピーク強度が減少して いることが観測できる.これらの結果から, 薄膜作製の際に最 適な基板温度は $300^{\circ} \mathrm{C}$ とした。

図 2 に基板温度を $300^{\circ} \mathrm{C}$ とし，ソースの組成比を $\mathrm{PbSO}_{4}+$ $x \mathrm{PbO}, x=0.0 \sim 1.0$ と変化させたときの $\mathrm{X}$ 線回折パターンを 


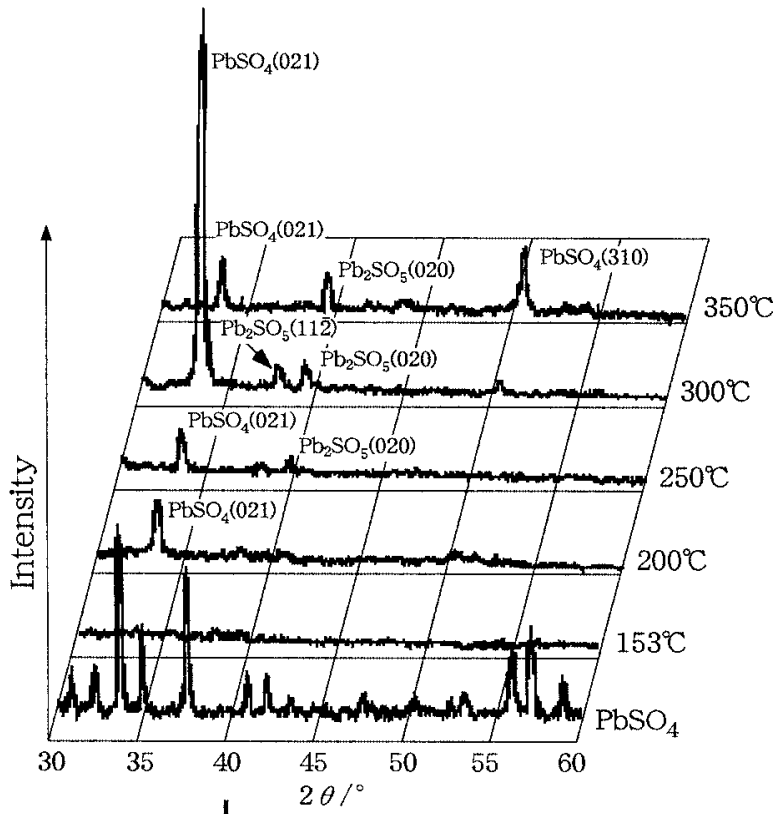

(a)

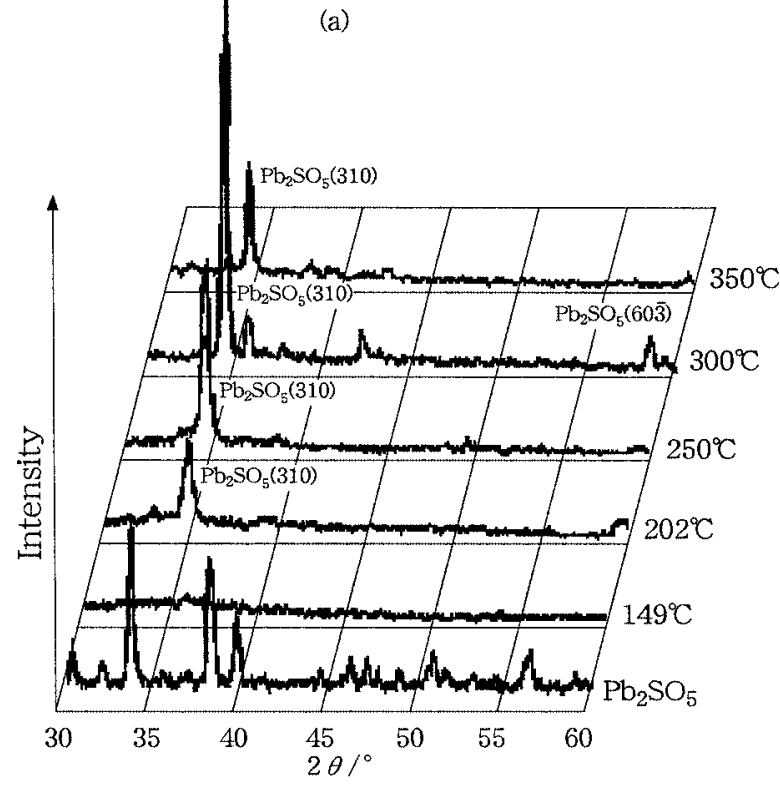

(b)

Fig. 1. XRD patterns $(\mathrm{Fe} \mathrm{K} \alpha)$ of thin films deposited at different substrate temperatures. Reference cards of (a) $\mathrm{PbSO}_{4}$ (ICDD card No. 36-1461) and (b) $\mathrm{PbSO}_{4}+\mathrm{PbO}$ (ICDD card No. 33-1486) are shown at the bottom, respectively. ${ }^{8}$ : (a) $\mathrm{PbSO}_{4}$, (b) $\mathrm{PbSO}_{4}+\mathrm{PbO}$.

示す. $\mathrm{PbSO}_{4}+x \mathrm{PbO}, x=0.0$ のソースで作製した薄膜には $\mathrm{Pb}_{2} \mathrm{SO}_{5}$ のピークが認められるものの，ほぼ $\mathrm{PbSO}_{4}$ の組成を有 する薄膜が生成していることが分かる. 一方, $\mathrm{PbSO}_{4}+x \mathrm{PbO}$, $x=1.0$ をソースとして得られた薄膜には $\mathrm{PbSO}_{4}$ のピークは観 測されず， $\mathrm{Pb}_{2} \mathrm{SO}_{5}$ のピークのみが強く現れている. また， $\mathrm{PbSO}_{4}+x \mathrm{PbO}, x=0.5$ 付近では両者の混合薄膜が結晶成長して いる.

これらの結果から，一つのソースを用いた電子ビーム蒸着法 によって，ソースの化学量組成とほぼ等しい組成の薄膜結晶を 生成できることが分かった。 また，硫酸鉛を用いた湿度セン サーの場合，その生成割合により感湿特性が影響を受けるた め，as-grown で所望の組成割合に制御できることは非常に有 用である。

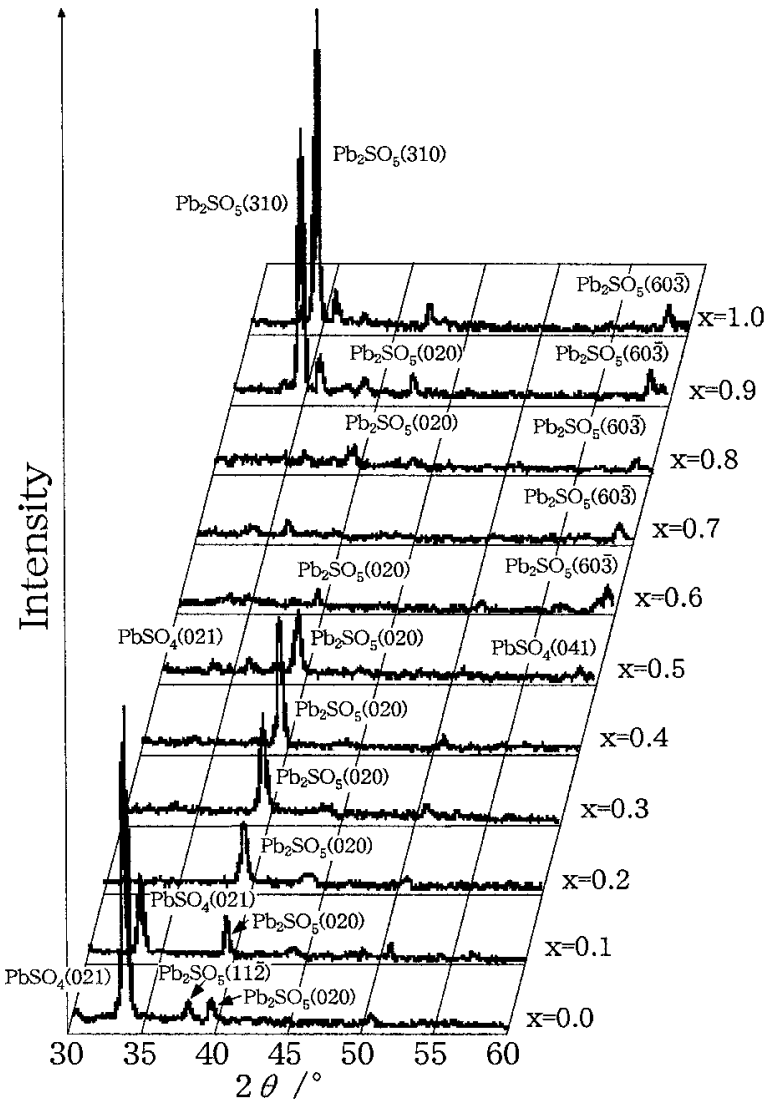

Fig. 2. XRD patterns $(\mathrm{Fe} \mathrm{K} \alpha)$ of thin films deposited using different source compositions.

\section{2 走査型電子顕微鏡による表面モホロジーの観察}

図 3 は走査型電子顕微鏡（SEM；日立製作所製，S550）を 用いて観察した薄膜の表面写真である。ソースを $\mathrm{PbSO}_{4}+$ $x \mathrm{PbO}, x=0.0$ (a) として作製した薄膜は表面が平坦であるのに 対し, $\mathrm{PbSO}_{4}+x \mathrm{PbO}, x=1.0$ (b)の薄膜の表面には, 鉛の析出 が観測できる.しかしながら，いずれの薄膜も緻密で平坦であ り, 結晶粒界がほとんど見られないために, 結晶粒界や気孔に よる感湿特性への影響を低減しうる構造となっている.

\section{3 感湿特性}

$\mathrm{PbSO}_{4}$ 薄膜と $\mathrm{Pb}_{2} \mathrm{SO}_{5}$ 薄膜の感湿特性を図 4 に示す。特性に 差が見られるが，どちらの薄膜も感湿性を持っている．この感 湿性の違いは母体制御型の感湿材料として報告されているクロ 么酸鉛5) と同様である. クロム酸鉛の報告では, 感湿性の違い を材料組成による特性と説明している. 一般に, 焼結が進行し ても焼結体には粒界. 気孔が数多く存在している. これに対し て, 図 3 のSEM 像に見られるように, 粒界·気孔がほとんど 見られない薄膜では，これらの影響が極めて少なく，感湿特性 の違いは材料組成による固有の水分子吸着メカニズムに, より 依存すると考えられる，低湿度側の吸着に注目すると，疎水性 薄膜は水分子を吸着しにくいために感湿性が鈍く, 逆に親水性 薄膜では，吸着しやすいために鋭くなると考えられる。つま り，図 4 に見られる低湿度側の特性から $\mathrm{PbSO}_{4}$ と $\mathrm{Pb}_{2} \mathrm{SO}_{5}$ は それぞれ疎水性, 親水性であると考えられる. また, 高湿度雲 囲気に抢いて，粒界・気孔が存在する焼結体は，毛細管凝縮の ために水分子を多く吸着でき，比較的鋭い感湿性が得られる が, 本研究で扱っている薄膜表面では, 水分子を吸着する吸着 サイトが限られ，容易に飽和してしまうものと考えられる. 図 


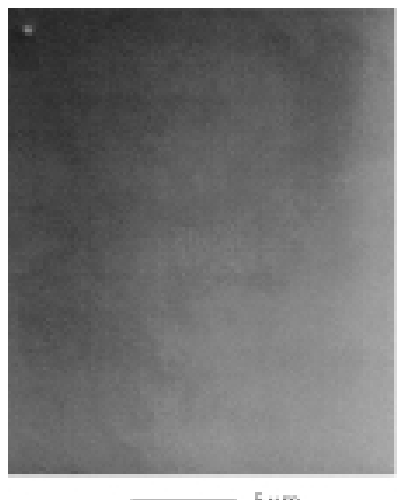

(a)

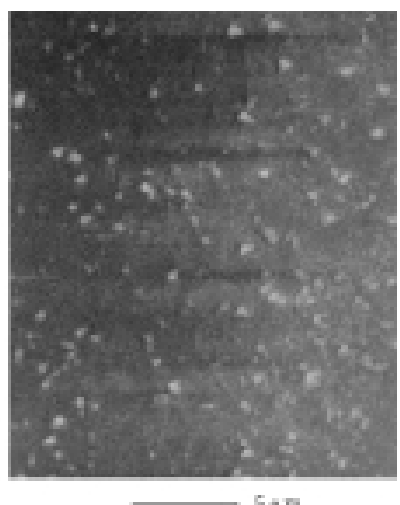

(b)
Fig. 3. SEM images of deposited thin films. $\mathrm{PbSO}_{4}+x \mathrm{PbO}:$ (a) $x=0.0$, (b) $x=1.0$.

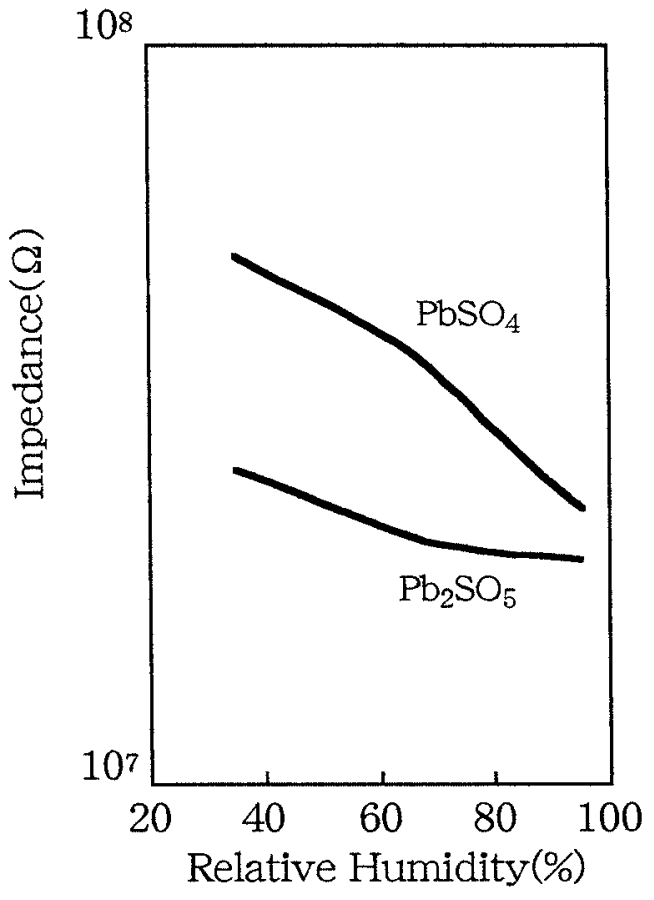

Fig. 4. Humidity sensing characteristics.
4 に見られる $\mathrm{Pb}_{2} \mathrm{SO}_{5}$ の高湿度側での特性はこの結果を示唆し ている。また， $\mathrm{PbSO}_{4}$ はいまだに飽和值に達していないもの と推察される.

これらの結果から，硫酸鉛は母体制御型の感湿メカニズムを もち, 薄膜化によって, 粒界. 気孔を取り除けることが示され た。したがって，良好な湿度応答を持つことが予想される。

図 5 は, $\mathrm{PbSO}_{4}$ の湿度応答特性である。薄膜の湿度応答 は, 吸着・脱着ともに数秒で安定しており, これまでに報告さ れているセラミック湿度センサー9) や市販の高分子湿度セン サーと比較しても応答性が良好である. 更に, 作製した薄膜, その薄膜用原料として用いた $\mathrm{PbSO}_{4}+x \mathrm{PbO}(x=0$ or $x=1)$ 粉 末を混合, 焼成した 2 種類のバルク, 及び市販の高分子湿度 センサーを用い，これらの湿度応答特性を詳細に検討した. 湿 度応答性は湿度 $50 \% \mathrm{RH}$ を基準とし, 各湿度から湿度 $50 \% \mathrm{RH}$ へと, 湿度 $50 \% \mathrm{RH}$ から各湿度へ変化させた。表 1 は低い湿度 から高い湿度へ湿度変化させた吸着に対する応答時間を, 反対 に高い湿度から低い湿度へ変化させた水分子の脱着についての 応答時間を表 2 に示す。なお, 湿度応答時間は最大变化幅の 90\%到達時間で表している. 高分子湿度センサーの応答時間 は吸着側で最大 $215 \mathrm{~s}$, 脱着側で最大 $761 \mathrm{~s}$ であり, 既存の湿度 センサーと同様に水分子の脱着に時間を要している. これに対 して $\mathrm{PbSO}_{4}$ バルクでは吸着側で最大 $582 \mathrm{~s}$, 脱着側で最大 629 $\mathrm{s}, \mathrm{Pb}_{2} \mathrm{SO}_{5}$ バルクでは吸着側で最大 $63 \mathrm{~s}$, 脱着側で最大 $718 \mathrm{~s}$ を 示している. バルクに㧍ける測定では, 低湿度側で $\mathrm{PbSO}_{4}$ は 水分子が吸着しにくく, 脱着しやすい, $\mathrm{Pb}_{2} \mathrm{SO}_{5}$ は水分子が吸

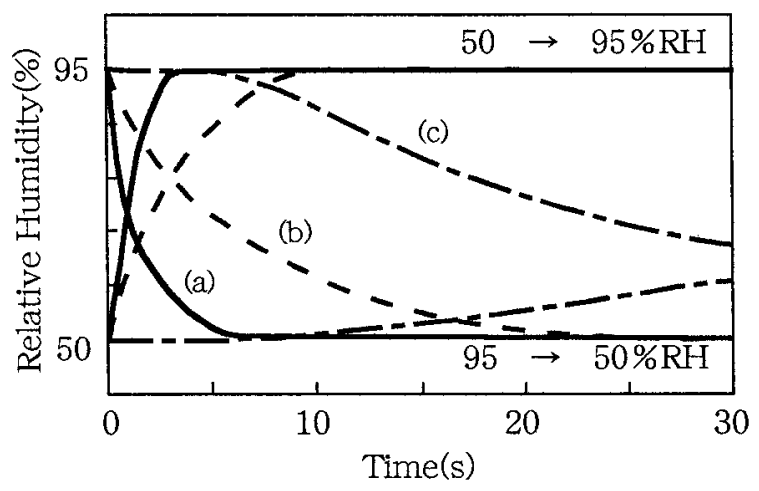

Fig. 5. Response characteristics of (a) $\mathrm{PbSO}_{4}$, (b) ceramic sensor in reference ${ }^{9)}$ and (c) commercial polymer sensor HS15 produced by Scimarec Inc.

Table 1. Adsorption Response Time

\begin{tabular}{ccccccc}
\hline & \multicolumn{5}{c}{ Humidity response/sec } \\
\cline { 2 - 7 } Relative humidity/\% & Sample & $\mathrm{HS} 15$ & $\mathrm{PbSO}_{4}$ Thin film & $\mathrm{Pb}_{2} \mathrm{SO}_{5}$ Thin film & $\mathrm{PbSO}_{4} \mathrm{Bulk}$ & $\mathrm{Pb}_{2} \mathrm{SO}_{5} \mathrm{Bulk}$ \\
\hline 35 & 215 & 3 & 2 & 10 & 8 \\
65 & 70 & 2 & 1 & 16 & 10 \\
80 & 60 & 2 & 5 & 19 & 13 \\
95 & 89 & 5 & 4 & 582 & 63 \\
\hline
\end{tabular}

Table 2. Desorption Response Time

\begin{tabular}{ccccccc}
\hline & \multicolumn{5}{c}{ Humidity response/sec } \\
\cline { 2 - 7 } Relative humidity/\%RH & Sample & $\mathrm{HS} 15$ & $\mathrm{PbSO}_{4}$ Thin film & $\mathrm{Pb}_{2} \mathrm{SO}_{5} \mathrm{Thin}$ film & $\mathrm{PbSO}_{4} \mathrm{Bulk}$ & $\mathrm{Pb}_{2} \mathrm{SO}_{5} \mathrm{Bulk}$ \\
\hline 35 & 699 & 3 & 4 & 5 & 46 \\
65 & 136 & 5 & 5 & 21 & 25 \\
80 & 355 & 1 & 3 & 82 & 172 \\
95 & 761 & 3 & 4 & 629 & 718 \\
\hline
\end{tabular}


着しやすく, 脱着しにくいという母体制御型感湿材料の性質を 示している. 高湿度領域（湿度80\%〜95\%）では粒界・気孔 の影響が有るため, 吸着・脱着ともに時間を要しているが，低 湿度側と同様な結果となった．特に吸着した水分子が粒界・気 孔内に残留するため, 吸着に比べて脱着に時間を要している が，この結果からも $\mathrm{PbSO}_{4}$ が疎水性であり， $\mathrm{Pb}_{2} \mathrm{SO}_{5}$ が親水性 であることが分かる.

これに対して，粒界，気孔がほとんど見られない薄膜の $\mathrm{PbSO}_{4}, \mathrm{~Pb}_{2} \mathrm{SO}_{5}$ ではともに吸着 ·脱着の応答時間は $5 \mathrm{~s}$ 以内と なっており，非常に早い湿度応答時間を示している。バルクと 比較してみると, 高湿度領域（湿度80\%～95\%）での湿度応 答が大幅に向上している.

これらの結果から, 蹯水性 $\mathrm{PbSO}_{4}$ 薄膜, 親水性 $\mathrm{Pb}_{2} \mathrm{SO}_{5}$ 薄 膜は, 薄膜化によって粒界 ·気孔の影響が低減され，非常に良 好な感湿レスポンスを有していることが分かった。 また約 100 回の感湿特性の測定後でも同様な特性が再現性よく観測され た.

硫酸鉛を湿度センサーとして応用する場合，クロム酸鉛と同 様に $\mathrm{PbSO}_{4}, \mathrm{~Pb}_{2} \mathrm{SO}_{5}$ の組成割合を制御することにより感湿特 性を制御できる可能性があり, $\mathrm{PbSO}_{4}, \mathrm{~Pb}_{2} \mathrm{SO}_{5}$ は湿度セン サーとして有望な材料であると考えられる.

\section{4. 結 論}

電子ビーム蒸着法を用いて作製した硫酸鉛結晶薄膜の母体制 御型湿度センサーについて評価し，下記のことが分かった。
（1）作製条件によって薄膜組成の制御が容易であり，かつ as-grown での結晶化が可能である.

(2) $\mathrm{PbSO}_{4}$ は疎水性, $\mathrm{Pb}_{2} \mathrm{SO}_{5}$ は親水性であり，いずれも 母体制御型の感湿機構を有する.

（3）加湿・除湿にかかわらず，極めて良好な応答性が認め られた。

\section{References}

1) Nantou, Y., "Sensa to Kisogijyutu," Kougakutosyo (1994) pp. 86-90 [in Japanese].

2) Yagi, H. and Nakata, M., J. Ceram. Soc. Japan, Vol. 100, pp. 152-156 (1992) [in Japanese].

3) The Institute of Electrical Engineers of Japan, "Sensing Materials - A Basis and Application-," Corona (2000) pp. 101-103 [in Japanese].

4) Kaneko, F., Jpn. J. Appl. Phys., Vol. 56, pp. 615-619 (1987) [in Japanese].

5) Kaneko, F. and Nanba, N., T. IEE Japan, Vol. 112-C, pp. 788-792 (1992) [in Japanese].

6) Doi, T., "Details of Semiconductor CMP Technology," Kogyo Chosakai (2001) pp. 9-14 [in Japanese].

7) Kaneko, F., Sakai, Y., Yamazaki, T. and Nanba, N., "The Composition Control Type Humidity Sensors," 2000 Autumn JSAP Annual Meeting (2000) 3p-T-10 [in Japanese].

8) "The American Society for Testing and Materials (ASTM) Card," card No. 36-1461, card No. 33-1486.

9) Yagi, H. and Ieda, Y., Sensor Technology, Vol. 2, No. 6, pp. 182-183 (1982). 